\title{
Effects of Task-Oriented Training in Water on Balance and Gait in Patients with Hemiplegia
}

\author{
Jin-Yeong Jeon ${ }^{1}$, Woo-Nam Chang ${ }^{2}$, Byong-Yong Hwang ${ }^{*}$ \\ ${ }^{1}$ Dept. of Physical Therapy, National Traffic injury Rehabilitation Hospital \\ ${ }^{* 2}$ Dept. of Physical Therapy, College of Health \& Welfare, Yong In University
}

\begin{abstract}
Purpose This study investigated the effects of task-oriented training in water on balance and gait in patients with hemiplegia. Methods Thirty-one patients with hemiplegia were randomly assigned into three groups: conventional therapeutic exercise (CTE), single-task training (STT), and dual-task training (DTT). The CTE group performed general exercise therapy, and the STT and DTT groups performed single-task and dual-task training, respectively, in the water. All groups performed the therapy five times a week, for 4 weeks. Results All groups showed significant difference in the timed up and go test (TUG), Berg balance scale (BBS), functional gait assessment (FGA), and weight-bearing deviation (WBD) within the group. Only the BBS showed significant difference between the DTT and CTE groups. Conclusion Task-oriented training in water was effective to improve balance and gait in patients with hemiplegia and dual-task training in water is more effective in some cases.
\end{abstract}

Key words Hemiplegia, Aquatic Therapy, Task Oriented Training, Balance, Gait

Corresponding author Byong-Yong Hwang (bhwang@yongin.ac.kr)

Received date

08 January 2019

Revised date

29 January 2019

Accepted date

08 February 2019

\section{Introduction}

The goal of rehabilitation of patients with hemiplegia is to improve their mobility, such as balance, motor, and walking deficits. However, the process of improvement of mobility in patients with hemiplegia is exposed to risk of falls. These patients show balance ability deficits (e.g., reduced postural stability to internal and external balance interference) and balance impairments are factors that increase fall risk $^{1-3)}$. Most functions in performing tasks in humans basically necessitate balance $^{4)}$. Task-oriented exercise is a form of therapy designed on the basis of the motor learning theory. It induces a cortical circuit with sufficient cortical sensory stimulation of the injured cortical area and adjacent areas and local terminal sprouting or functional tactile reorganization ${ }^{5}$ and is a program that focuses on the functional task of efficiently activating neuromuscular components ${ }^{6}$. In addition, task-oriented exercise is a dual-task activity that affects

http:dx.doi.org/10.17817/2019.01.29.111351 posture control and balance ability improvement of the patient ${ }^{7}$. Single-task training is training on the component of the whole task before performing the whole task. The major benefit of this training is to reduce the requirements imposed on the subjects. The reduction of task processing requirements can promote faster learning of a specific task in single-task training than the whole task ${ }^{8}$. However, most activities of daily living (ADLs) necessitate the ability to maintain balance during the simultaneous performance of various tasks. The ability to divide attention while simultaneously performing two or more tasks is an important part of functional movement in ADLs ${ }^{9-10)}$. Performing two tasks simultaneously reduces one or all task performance ${ }^{11)}$. However, this problem from dual-task interference can be resolve by training two tasks simultaneously ${ }^{12)}$. Dual-task training is training that the ability to simultaneously perform two or more activities while maintaining postural control. It has a more positive effect on ADL than single-task training. Moreover, this training is an effective strategy that can improve subject's attentional control and task coordi- 


$$
\text { nation }^{8,13)} \text {. }
$$

An aquatic environment can help in physical activity such as strength, balance, and endurance ${ }^{14)}$. The body is influenced by basic forces of water during immersion like buoyancy, drag, and inertial force ${ }^{15}$. Water is a medium that has density and viscosity, which rapidly decelerates movements. These properties protect the body from events such as falling or injury. Thereby, balance training in water not only reduces risk and fear of falls but also replaces land-based training for falls ${ }^{15)}$ Viscous resistance increases as greater force is applied. However, inertial moment is less so that, if the force is stopped, resistance immediately drops to zero. Thus, if the movement is stopped when pain is felt during the exercise, viscous resistance will decrease and be able to protect body part $^{16)}$. The physical properties of water make it possible to safely train muscle strengthening, balance, and functional skills ${ }^{17)}$. There are a number of studies that have investigated the effects of dual-task training in land and in water ${ }^{11-13,15,18-20)}$. However, studies that compare task-oriented training that single- and dual-task, respectively, in water are rare. Therefore, the present study investigated the effects of task-oriented training in water on balance and gait in patients with hemiplegia.

\section{Materials and Methods}

\section{Subjects}

Thirty-one patients with hemiplegia from the rehabilitation center of the National Traffic injury Rehabilitation Hospital in Yangpyeong, Gyeonggi, Republic of Korea, were enrolled in this study. The inclusion criteria were as follow: (1) ability to walk at least $15 \mathrm{~m}$ without assistance; (2) a score of $>24$ in the Mini-Mental State Examination - Korean (MMSE-K); (3) a score of $>36$ in the BBS; (4) absence of orthopedic and neurologic pain that influence to participated in this study in whole body. All subjects were diagnosed stoke except one person who had brain injury because of accident and signed an informed consent form that was approved by the Yong In
University institutional review board.

\section{Measurement \\ (1) Balance}

Balance was determined by the Berg balance scale (BBS) and the timed up and go test (TUG). The BBS has 14 functional balance items. Each item has 0 to 4 points, with a total score from 0 to 56 . The higher the score, the better the balance ability. The BBS has $\mathrm{r}=.99$ intra-rater reliability and $\mathrm{r}=.98$ inter-rater reliability $^{21-22)}$. The TUG was developed to evaluate functional ambulation in elderly individuals and has been used recently in patients with various diseases, such as stroke, Parkinson's disease, and arthritis. In addition, this can simply assess functional movement in a small space without the use of a specific equipment. The TUG has $r=.99$ intra-rater reliability and $r=.99$ inter-rater reliability ${ }^{23)}$.

\section{(2) Gait}

Gait was measured by the functional gait assessment (FGA). The FGA is a modification of the dynamic gait index(DGI) to be used in higher-level tasks to extend the applicability of the test and remove the ceiling effect of the original test. This tool has 10 items. Each item has 0 to 3 points, with a total score from 0 to 30. The higher the score, the better the gait ability. The FGA has $r=.83$ intra-rater reliability and $r=.84$ inter-rater reliability ${ }^{24)}$.

\section{(3) weight bearing deviation}

The Weight bearing deviation (WBD) was measured by the BioRescue (RM Ingenierie, Rodez, France). The footprints reveal relative repartitions of foot pressure, which would indicate postural imbalance ${ }^{25}$. The subjects were instructed to stand as immobile as possible in a natural position in front of a visual target placed on the wall at eye level during the trials. If weight-bearing ratio of left and right sides was 50\%, WBD is zero. The closer the WBD to 0 , the better the balance between the left and right sides.

\section{Intervention}


Subjects were randomly assigned to one of three training groups. These groups were as follow : (1) conventional therapeutic exercise (CTE); (2) single-task training; (3) dual-task training (DTT). All groups received neuro-development therapy (NDT) for 30 min once daily, five times a week, for 4 weeks, equally. Each group conducted additional training with the same frequency. Subjects who were assigned to the CTE group performed general exercise. Both STT and DTT groups performed the training in the therapeutic pool. The pool was $6 \mathrm{~m}$ wide, $11.5 \mathrm{~m}$ long, and 1.05-1.15 $\mathrm{m}$ deep. The water and atmosphere temperature was about $33 \pm 1{ }^{\circ} \mathrm{C}\left(91.4 \pm 1.8{ }^{\circ} \mathrm{F}\right)$ and $26 \pm 2^{\circ} \mathrm{C}\left(78.8 \pm 3.5^{\circ} \mathrm{F}\right)$, respectively. The intervention program that each group were as follow table 1. All measurements conducted pre- and post-intervention on dry land.

\section{Data analysis}

Data were analyzed using SPSS version 18.0. The subject's general characteristics were analyzed with descriptive statistics. Difference in parameters before and after the training within the group was analyzed using
Mann-Whitney $\mathrm{U}$ test, while the Kruskal-Wallis test and Bonferroni correction were used to compare the difference in parameters before and after the training between the groups. P-values $<.05$ and $<.0167$ indicated statistical significance levels within the group and between groups, respectively.

\section{Results}

\section{General characteristics of the subjects}

In this study, 31 subjects were randomly assigned to three groups (CTE, STT, DTT), but only 27 subjects participated in the study due to discharge and health deterioration. Of the total subjects, 21(77.78\%) were male and $6(22.22 \%)$ were female. The average height of all subjects was $168.52 \pm 8.00 \mathrm{~cm}$, The average weight of all subjects was $70.80 \pm 12.24 \mathrm{~kg}$ and of the total subjects, hemiplegic side were that 15(48.39\%) left and that $16(51.61 \%)$ right. The average MMSE-K score was $28.07 \pm 1.92$ (Table 2).

\section{Table 1. Intervention program}

CTE

(1) sit to stand

(2) walking

(3) conditioning exercise using an equipment

STT

(1) tread on the buoyancy pad in the underwater step with the paralyzed foot

(2) change of metacenter

(3) throwing and receiving a ball

(4) obstacle crossing

(5) walking along a line

DTT

(1) change of metacenter while treading on the buoyancy pad in the underwater step with the paralyzed foot

(2) throwing and receiving a ball while treading on the buoyancy pad in the underwater step with the paralyzed foot

(3) obstacle crossing while maintaining a ball on the board

(4) walking along a line while maintaining a ball on the board

Note. CTE: conventional therapeutic exercise, STT: single-task training, DTT: dual-task training 
Table 2. General characteristics of the subjects $(n=31)$

\begin{tabular}{|c|c|c|c|c|}
\hline & & CTE (n=10) & STT (n=11) & DTT (n=10) \\
\hline Age & & $48.33 \pm 12.92$ & $38.44 \pm 11.61$ & $48.33 \pm 12.68$ \\
\hline \multicolumn{5}{|l|}{ Sex } \\
\hline & Male & 7 & 7 & 8 \\
\hline & Female & 3 & 4 & 2 \\
\hline Height $(\mathrm{cm})$ & & $166.79 \pm 7.98$ & $174.33 \pm 7.94$ & $164.43 \pm 4.60$ \\
\hline Weight (kg) & & $64.60 \pm 7.35$ & $79.72 \pm 12.02$ & $68.07 \pm 12.14$ \\
\hline \multicolumn{5}{|l|}{ hemiplegic side } \\
\hline & Left & 6 & 6 & 3 \\
\hline & Right & 4 & 5 & 7 \\
\hline MMSE-K score & & $28.11 \pm 1.54$ & $28.33 \pm 1.87$ & $27.78 \pm 2.44$ \\
\hline
\end{tabular}

MMSE-K, Mini-Mental State Examination - Korean

\section{Comparison within and between groups \\ (1) Comparison within each group}

The TUG in all groups significantly decreased $(\mathrm{p}<.01)$. CTE decreased significantly from 20.49 7.43 to $16.32 \pm 5.21 \mathrm{~s}$ after the intervention $(\mathrm{p}<.01)$, STT significantly decreased from $26.07 \pm 12.30$ to $21.66 \pm 9.78 \mathrm{~s}$ after the intervention $(\mathrm{p}<.05)$, and DTT significantly decreased from $19.80 \pm 9.61$ to $14.04 \pm 6.90 \mathrm{~s}$ after the intervention $(\mathrm{p}<.01)$. BBS in all groups significantly increased $(\mathrm{p}<.01)$. CTE significantly increased from $44.00 \pm 5.96$ to $46.22 \pm 4.87$ after the intervention $(\mathrm{p}<.05)$, STT significantly increased from $39.00 \pm 7.57$ to $45.11 \pm 5.56$ after the intervention $(\mathrm{p}<.01)$, and DTT significantly increased from $41.78 \pm 5.54$ to $49.00 \pm 4.85$ after the intervention $(\mathrm{p}<.01)$. FGA in all groups significantly increased $(\mathrm{p}<.01)$. CTE significantly increased from $17.22 \pm 5.14$ to $20.11 \pm 4.60$ after the intervention $(\mathrm{p}<.01)$, STT significantly increased from $13.00 \pm 6.04$ to $17.33 \pm 7.19$ after the intervention $(\mathrm{p}<.01)$, and DTT significantly increased from $15.11 \pm 6.81$ to $21.33 \pm 6.19$ after the intervention $(\mathrm{p}<.05)$. WBD in all groups significantly decreased $(\mathrm{p}<.01)$. CTE significantly decreased from $14.31 \pm 9.26$ to $5.07 \pm 4.64$ after the intervention $(\mathrm{p}<.05)$, STT significantly decreased from $11.92 \pm 6.08$ to $7.21 \pm 3.15$ after the intervention $(\mathrm{p}<.01)$, and DTT significantly decreased from $14.156 \pm 5.70$ to $7.21 \pm 3.15$ after the intervention $(\mathrm{p}<.05)$.

\section{(2) Comparison between groups}

TUG in STT was more decreased than that in CTE, while TUG in DTT was more decreased than those in CTE and STT. However, there was no significant difference between groups. BBS in STT was more increased than that in CTE, while BBS in DTT was more increased than those in CTE and STT. There was a significant difference in BBS between DTT and CTE $(p<.0167)$. FGA in STT was more increased than that in CTE, and FGA in DTT was greatly increased than those in CTE and STT. However, there was no significant difference between the groups. WBD in CTE was more decreased than that in STT. WBD in DTT was more decreased than that in STT, and WBD in DTT was more decreased than that in CTE. However, there was no significant difference between the groups (Table 3).

\section{Discussion}

Balance includes symmetry to keep left-right weight distribution constant, stability to keep a given posture using minimal body perturbation, and dynamic stability to move while maintaining balance ${ }^{26)}$. Balance disorders are a major cause of falls, approximately 50 to $70 \%$ of patients with hemiplegia experience falls ${ }^{27)}$. The weight-bearing capacity of the paralyzed leg is commonly reduced after stroke, and the majority (79 to $87 \%$ ) of patients with stroke are bearing lesser 
Table 3. Comparison within and between the three groups $(n=27)$

\begin{tabular}{|c|c|c|c|c|c|}
\hline Variables & CTE (n=9) & STT (n=9) & DTT (n=9) & $\chi^{2}$ & p \\
\hline \multicolumn{6}{|l|}{ TUG } \\
\hline Pre & $20.49 \pm 7.43$ & $26.07 \pm 12.30$ & $19.80 \pm 9.61$ & \multirow{3}{*}{.160} & \multirow{3}{*}{.923} \\
\hline Post & $16.32 \pm 5.21$ & $21.66 \pm 9.78$ & $14.04 \pm 6.90$ & & \\
\hline Post-pre & $-4.13 \pm 2.95^{* * *}$ & $-4.41 \pm 3.26^{*}$ & $-5.76 \pm 5.99^{\text {*** }}$ & & \\
\hline \multicolumn{6}{|l|}{ BBS } \\
\hline Pre & $44.00 \pm 5.96$ & $39.00 \pm 7.57$ & $41.78 \pm 5.54$ & \multirow{3}{*}{10.984} & \multirow{3}{*}{$.004^{+}$} \\
\hline Post & $46.22 \pm 4.87$ & $45.11 \pm 5.56$ & $49.00 \pm 4.85$ & & \\
\hline Post-pre & $2.22 \pm 1.64^{*}$ & $6.11 \pm 6.15^{* * *}$ & $7.22 \pm 3.23^{* * *}$ & & \\
\hline \multicolumn{6}{|l|}{ FGA } \\
\hline Pre & $17.22 \pm 5.14$ & $13.00 \pm 6.04$ & $15.11 \pm 6.80$ & \multirow{3}{*}{6.621} & \multirow{3}{*}{.036} \\
\hline Post & $20.11 \pm 4.60$ & $17.33 \pm 7.19$ & $21.33 \pm 6.19$ & & \\
\hline Post-pre & $2.89 \pm 1.45^{* * *}$ & $4.33 \pm 1.94^{* * * *}$ & $6.44 \pm 4.07^{*}$ & & \\
\hline \multicolumn{6}{|l|}{ WBD } \\
\hline Pre & $14.31 \pm 9.26$ & $11.92 \pm 6.08$ & $14.16 \pm 5.70$ & \multirow{3}{*}{.489} & \multirow{3}{*}{.783} \\
\hline Post & $5.07 \pm 4.64$ & $6.24 \pm 5.57$ & $7.21 \pm 3.15$ & & \\
\hline Post-pre & $7.34 \pm 6.23^{\prime \prime}$ & $5.70 \pm 2.58^{* * *}$ & $5.53 \pm 4.29^{*}$ & & \\
\hline
\end{tabular}

Within group, ${ }^{*} p<.05, * * p<.01$, Between groups, $+p<.0167$

Note. TUG: the timed up and go test, BBS: Berg balance scale, FGA: functional gait assessment, WBD: weight bearing deviation.

${ }^{a}$ mean \pm standard deviation.

weight on the paralyzed side in static standing posture $^{28-29)}$. Weight shift is an essential factor for functional mobility and walking, and mediolateral weight shift in patients with stroke is directly associated with walking ${ }^{30-31)}$. Therefore, improvement in postural stability is one of the important goals of rehabilitation ${ }^{32-33)}$.

In the present study, BBS scores were significantly higher in all groups (CTE, $\mathrm{p}<.05$; STT, $\mathrm{p}<.01$; and DTT, $\mathrm{p}<.01)$. The BBS score in the DTT group was higher than that in the CTE group. Especially, there was a great difference in items including task performance, such as reaching forward with arm and pick up object. Saeterbakken et al. ${ }^{34)}$ reported that the stronger the trunk muscle, the better the task performance. It is considered that dual-task training in water influenced to trunk stability. Therefore, task-oriented training in the water can help improve the dynamic balance ability in patients with hemiplegia.

The TUG has high reliability in quantifying the dynamic balance capability and functional mobility in patients with stroke and measuring the clinical changes over time ${ }^{35)}$. TUG time were significantly de- creased in all groups (CTE, $\mathrm{p}<.01$; STT, $\mathrm{p}<.05$; DTT, $\mathrm{p}<.01)$. It is thought that task-oriented exercise in the water may help improve balance ability

in patients with hemiplegia. Walker et al. ${ }^{36)}$ reported that there is a correlation between TUG and walking speed.

Walking speed, clinically, was used to determine independent walking ability and recovery level in performing $\mathrm{ADLs}^{37)}$. In the present study, a decrease in the TUG value indicates an increase in walking ability, which may improve functional performance.

Yang et al. ${ }^{38)}$ reported that gait training combined with functional tasks was effective in increasing walking speed and stride length in patients with stroke. In addition, Salbach et al. ${ }^{39)}$ demonstrated that 10 task-oriented and functional upper limb movements related to gait have an effect on the balance ability of patient with stroke. In the present study, the FGA scores were significantly increased in all groups (CTE, $\mathrm{p}<.01$; STT, $\mathrm{p}<.01$; DTT, $\mathrm{p}<.05$ ). The FGA score in the DTT group was much higher than that in the CTE group. However, there was no significant difference 
between groups. Stevens et al. ${ }^{40)}$ reported that in underwater walking training increased walking speed. Exercise in the water helps activate the trunk muscles $^{41)}$, and walking exercise in the water produces greater trunk muscle activity than on dry land ${ }^{42-433}$. This is related to drag, and drag is influenced by velocity and surface area ${ }^{44)}$. Therefore, it is considered that dual-task training in water is more effective in the enhancement of the trunk muscle and functional gait training than that on dry land.

WBD scores were significantly decreased in all groups (CTE, $\mathrm{p}<.05 ; \quad$ STT, $\mathrm{p}<.01 ;$ DTT, $\mathrm{p}<.05$ ). Weight-bearing asymmetry is associated with increased postural sway, and the larger the weight-bearing asymmetry, the lower the BBS score ${ }^{45-46)}$. The weight shift training makes symmetrical weight support in standing posture, and the right and left weight shift is directly related to walking ${ }^{31,47)}$. Dean et al. ${ }^{48)}$ conducted a functional stretch task training in three directions to study an experimental group that induces weight bearing on the paralyzed lower limb and a control group that performs functional stretch task training without weight bearing. As a result, the experimental group was more effective in weight-bearing ability, strength, and balance ability than the control group. Noh et al. ${ }^{49)}$ reported that exercise in the water can effectively improve the weight-bearing capacity of patients with stroke. Therefore, decreasing WBD in this study suggests that the task-oriented exercise in the water is effective to increase weight support ability and walking ability on the affected leg in patients with hemiplegia.

Kwakkel et $\mathrm{al}^{50)}$. suggested that task-oriented functional training enhances interaction between the nervous and muscular systems. The ability to maintain balance can be enhanced through task-oriented training ${ }^{51)}$. Dual-task ability can be enhanced through training, which implies a change in neuronal activation $^{52}$. Raine and Lynch $^{53)}$ suggested that it is necessary to perform dual tasks in daily life. The aquatic environment reduces the effort to support the body and provides a safe environment for weight bearing ${ }^{54}$. Buoyancy allows the patient to move with less effort and perform without help actions that are impossible on dry land ${ }^{55)}$. Based on the above evidence, it can be said that the aquatic environment is an environment where it is easier and safer to perform the task than on dry land.

The results of this study suggest that task-oriented training in water is effective for balance and gait in patients with hemiplegia and that dual-task training is more effective in some cases. Therefore, dual-task training in water as well as general rehabilitation therapy is effective in improving balance and gait in patients with hemiplegia.

The limitation of this study is that it is difficult to generalize to all patients with hemiplegia. This is because only patients who were admitted to the National Traffic injury Rehabilitation Hospital who met the study conditions participated in the study. In addition, statistically type II error could not be excluded because of the number of subjects was small. It was difficult to control the various treatment schedules of patients other than the program and because the patient's heights were varied, it was difficult to standardize the elements of water characteristics such as buoyancy, viscous resistance, hydrostatic pressure, and drag. In addition, the subject needed a high level of balance ability to perform various tasks, which had caused a ceiling effect in some measurement items.

In order to generalize the results of the study, more patients should be studied and various research methods are needed to investigate the effect of dual-task training in water.

\section{Conclusion}

The purpose of this study was to investigate the effects of task-oriented training in water on balance and gait in patients with hemiplegia. The subjects were randomly assigned into CTE (10), STT (11), and DTT (10) groups, with 31 patients meeting the purpose of this study among the patients who were hospitalized in the National Traffic injury Rehabilitation Hospital in Yangpyeong-gun, Gyeonggi-do, Republic of Korea. The results of the study are as follows.

First, the TUG test showed a significant decrease 
in all three groups $(\mathrm{p}<.01)$. However, there was no significant difference between the groups.

Second, the BBS test showed a significant increase in all three groups $(\mathrm{p}<.01)$. The DTT group showed a significantly higher BBS score than the CTE group $(\mathrm{p}<.0167)$.

Third, the FGA test showed a significant increase in all three groups $(\mathrm{p}<.01)$. However, there was no significant difference between groups.

Fourth, the WBD test showed a significant decrease in all three groups $(p<.01)$. However, there was no significant difference between groups.

It suggests that task-oriented training in water for 4 weeks was effective to improve balance and gait in patients with hemiplegia, and dual-task training is more effective in some cases. Based on these results, task-oriented training in water may help improve balance and gait in patients with hemiplegia.

\section{Reference}

1. Tilson $\mathrm{JK}, \mathrm{Wu}$. Characterizing and identifying risk for falls in the LEAPS study: a randomized clinical trial of interventions to improve walking poststroke. Stroke. 2012;43(2):446-452.

2. Weerdesteijn VGM, Niet. Falls in individuals with stroke.2008.

3. Horak FB. Postural orientation and equilibrium: what do we need to know about neural control of balance to prevent falls?. Age and ageing. 2006;35(2), ii7-ii11.

4. Shumway-Cook A, Woollacott MH. Motor control: translating research into clinical practice. Lippincott Williams \& Wilkins. 2007.

5. Rossini PM, Pauri F. Neuromagnetic integrated methods tracking human brain mechanisms of sensorimotor areas 'plastic'reorganisation. Brain research reviews. 2000;33(2-3):131-154.

6. Carr JH, Shepherd RB. A motor relearning programme for stroke. Aspen Pub. 1987.

7. Stoffregen TA, Pagulayan. Modulating postural control to facilitate visual performance. Human Movement Science. 2000;19(2):203-220.

8. Kramer AF, Larish. Training for attentional control in dual task settings: a comparison of young and old adults. Journal of experimental psychology. 1995;1(1):50.
9. Morioka S, Hiyamizu M, Yagi F. The effects of an attentional demand tasks on standing posture control. Journal of physiological anthropology and applied human science. 2005;24(3):215-219.

10. Shin SS, An. The effect of motor dual-task balance training on balance and gait of elderly women. Journal of physical therapy science. 2014;26(3):359-361.

11. Pellecchia GL. Dual-task training reduces impact of cognitive task on postural sway. Journal of motor behavior. 2005;37(3):239-246.

12. Silsupadol P, Shumway-Cook A, Lugade, et al. Effects of single-task versus dual-task training on balance performance in older adults: a double-blind, randomized controlled trial. Archives of physical medicine and rehabilitation. 2009;90(3):381-387.

13. Silsupadol P, Siu KC, Shumway-Cook, et al. Training of balance under single-and dual-task conditions in older adults with balance impairment. Physical therapy. 2006;86(2):269-281.

14. Geytenbeek, J. Evidence for effective hydrotherapy. Physiotherapy. 2002;88(9):514-529.

15. Melzer I, Elbar O, Tsedek I, et al. A water-based training program that include perturbation exercises to improve stepping responses in older adults: study protocol for a randomized controlled cross-over trial.BMC geriatrics. 2008; 8(1):19.

16. Cole, A J, \& Becker, B. E. (Eds.). Comprehensive aquatic therapy. Butterworth-Heinemann. 2004.

17. Salem Y, Scott AH, Karpatkin, et al. Community-based group aquatic programme for individuals with multiple sclerosis: a pilot study. Disability and rehabilitation. 2011;33(9):720-728

18. Madehkhaksar F, Egges A. Effect of dual task type on gait and dynamic stability during stair negotiation at different inclinations. Gait \& posture. 2016;43:114-119.

19. Schaefer SY, Louder TJ, Foster S, et al. Effect of water immersion on dual task performance: implications for aquatic therapy. Physiotherapy Research International. 2016;21(3):147-154.

20. Kim K, Lee DK, Kim EK. Effect of aquatic dual-task training on balance and gait in stroke patients. Journal of physical therapy science. 2016;28(7):2044-2047.

21. Cattaneo D, Regola A, Meotti M. Validity of six balance disorders scales in persons with multiple sclerosis. Disability and rehabilitation. 2006;28(12): 789-795. 
22. Berg K, Wood-Dauphinee S, Williams JI. The Balance Scale: reliability assessment with elderly residents and patients with an acute stroke. Scandinavian journal of rehabilitation medicine. 1995; 27(1): 27-36.

23. Morris S, Morris ME, Iansek R. Reliability of measurements obtained with the Timed "Up \& Go" test in people with Parkinson disease. Physical therapy. 2001; 81(2): 810-818.

24. Wrisley DM, Marchetti GF, Kuharsky DK, et al. (2004). Reliability, internal consistency, and validity of data obtained with the functional gait assessment. Physical therapy. 2004;84(10): 906-918.

25. Lee J, Seo K. The effects of stair walking training on the balance ability of chronic stroke patients. Journal of physical therapy science. 2014;26(4): 517-520.

26. Shumway-Cook A, Woollacott MH. Theory and Practical Applications. 2001.

27. Mackintosh SF, Hill KD, Dodd KJ, et al. Balance score and a history of falls in hospital predict recurrent falls in the 6 months following stroke rehabilitation. Archives of physical medicine and rehabilitation. 2006;87(12): 1583-1589.

28. Laufer Y, Dickstein R, Resnik S, et al. Weight-bearing shifts of hemiparetic and healthy adults upon stepping on stairs of various heights. Clinical rehabilitation. 2000;14(2):125-129.

29. Goldie PA, Matyas TA, Evans OM, et al. Maximum voluntary weight-bearing by the affected and unaffected legs in standing following stroke. Clinical Biomechanics. 1996;11(6):333-342.

30. Eng JJ, Chu KS. Reliability and comparison of weight-bearing ability during standing tasks for individuals with chronic stroke. Archives of physical medicine and rehabilitation. 2002;83(8):1138-1144.

31. Shin WS, Lee SW, Lee YW, et al. Effects of combined exercise training on balance of hemiplegic stroke patients. Journal of Physical Therapy Science. 2011;23(4): 639-643.

32. Van de Port IG, Kwakkel G, Schepers VP, et al. Predicting mobility outcome one year after stroke: a prospective cohort study. 2006.

33. Kollen B, Kwakkel G, Lindeman E. Longitudinal robustness of variables predicting independent gait following severe middle cerebral artery stroke: a prospective cohort study. Clinical rehabilitation.
2006;20(3):262-268.

34. Saeterbakken AH, Van den Tillaar R, Seiler S. Effect of core stability training on throwing velocity in female handball players. The Journal of Strength \& Conditioning Research. 2011;25(3):712-718.

35. Ng SS, Hui-Chan CW. The timed up \& go test: its reliability and association with lower-limb impairments and locomotor capacities in people with chronic stroke. Archives of physical medicine and rehabilitation. 2005;86(8):1641-1647.

36. Walker C, Brouwer BJ, Culham EG. Use of visual feedback in retraining balance following acute stroke. Physical therapy. 2000;80(9):886-895.

37. Kim CM, Eng JJ. The relationship of lower-extremity muscle torque to locomotor performance in people with stroke. Physical therapy. 2003;83(1):49-57.

38. Yang YR, Wang RY, Lin $\mathrm{KH}$, et al. Task-oriented progressive resistance strength training improves muscle strength and functional performance in individuals with stroke. Clinical rehabilitation. 2006;20(10):860-870.

39. Salbach NM, Mayo NE, Robichaud Ekstrand S, et al. The effect of a task oriented walking intervention on improving balance self efficacy poststroke: A randomized, controlled trial. Journal of the American Geriatrics Society. 2005;53(4):576-582.

40. Stevens SL, Caputo JL, Fuller DK, et al. Effects of underwater treadmill training on leg strength, balance, and walking performance in adults with incomplete spinal cord injury. The journal of spinal cord medicine. 2015;38(1):91-101.

41. Cuesta-Vargas AI, Cano-Herrera CL, Heywood S. Analysis of the neuromuscular activity during rising from a chair in water and on dry land. Journal of Electromyography and Kinesiology. 2013;23(6):1446-1450.

42. Orselli MIV, Duarte M. Joint forces and torques when walking in shallow water. Journal of Biomechanics. 2011;44(6):1170-1175.

43. Kaneda K, Sato D, Wakabayashi, et al. EMG activity of hip and trunk muscles during deep-water running. Journal of Electromyography and Kinesiology. 2009; 19(6):1064-1070.

44. Towler MA, Goitz RJ, Wilder RP, et al. Bioengineering principles of hydrotherapy. The Journal of burn care \& rehabilitation. 1987;8(6):579-584.

45. Kamphuis JF, de Kam D, Geurts AC, et al. Is 
weight-bearing asymmetry associated with postural instability after stroke? A systematic review. Stroke research and treatment. 2013.

46. Mansfield A, Mochizuki G, Inness EL, et al. Clinical correlates of between-limb synchronization of standing balance control and falls during inpatient stroke rehabilitation. Neurorehabilitation and neural repair. 2012;26(6):627-635.

47. Winstein CJ, Gardner ER, McNeal DR, et al. Standing balance training: effect on balance and locomotion in hemiparetic adults. Arch Phys Med Rehabil. 1989;70(10):755-762.

48. Dean CM, Shepherd RB. Task-related training improves performance of seated reaching tasks after stroke: a randomized controlled trial. Stroke. 1997;28(4):722-728.

49. Noh DK, Lim JY, Shin HI, et al. The effect of aquatic therapy on postural balance and muscle strength in stroke survivors - a randomized controlled pilot trial. Clinical rehabilitation. 2008;22(10-11):966-976.

50. Kwakkel G, Wagenaar RC, Koelman TW, et al. Effects of intensity of rehabilitation after stroke: a research synthesis. Stroke. 1997;28(8):1550-1556.
51. Flynn S, Palma P, Bender A. Feasibility of using the Sony PlayStation 2 gaming platform for an individual poststroke: a case report. Journal of neurologic physical therapy. 2007;31(4):180-189.

52. Erickson KI, Colcombe SJ, Wadhwa R, et al. Training-induced plasticity in older adults: effects of training on hemispheric asymmetry. Neurobiology of aging. 2007;28(2):272-283.

53. Raine S, Meadows L, Lynch-Ellerington M. Bobath concept: theory and clinical practice in neurological rehabilitation. John Wiley \& Sons. 2013.

54. Foley A, Halbert J, Hewitt T, et al. Does hydrotherapy improve strength and physical function in patients with osteoarthritis - a randomised controlled trial comparing a gym based and a hydrotherapy based strengthening programme. Annals of the rheumatic diseases. 2003;62(12):1162-1167.

55. Suomi R, Koceja DM. Postural sway characteristics in women with lower extremity arthritis before and after an aquatic exercise intervention. Archives of physical medicine and rehabilitation. 2000;81(6):780-785. 
